\title{
Soil Physical Properties
}

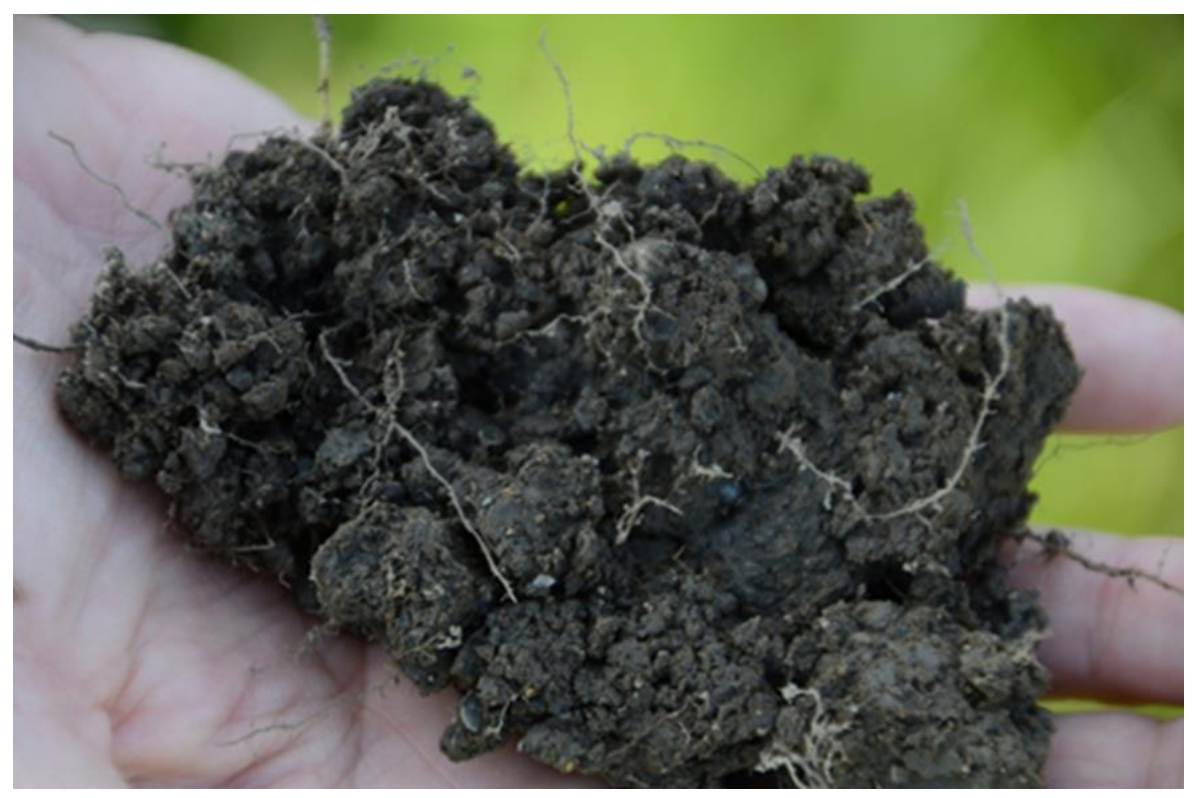

Adam Hayes, OMAFRA

Soil Health Research KTT Forum 2016 


\section{Soil Function, Soil Properties and}

Soil Health

\section{CHEMICAL}

Soil compaction

Water infiltration

Aggregate stability

\section{PHYSICAL}

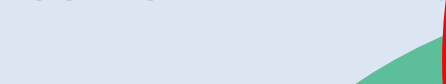

$\mathrm{pH}$

Potassium

Phosphorus

$\mathrm{Ca}, \mathrm{Zn}, \mathrm{Mg}, \mathrm{Mn}$

\section{BIOLOGICAL}

Potentially mineralizable nitrogen

\% Organic Matter Respiration 


\section{Soil Physical Properties}

- Soil texture

- Soil structure

- Aggregate stability

- Bulk density

- Available water capacity

- Soil colour 


\section{Soil Texture}

Mineral fraction:

- Stones

- Gravel

- Sand (very fine to coarse) -0.05 to $2.0 \mathrm{~mm}$

- Silt -0.002 to $0.05 \mathrm{~mm}$

- Clay $-<0.002 \mathrm{~mm}$ 


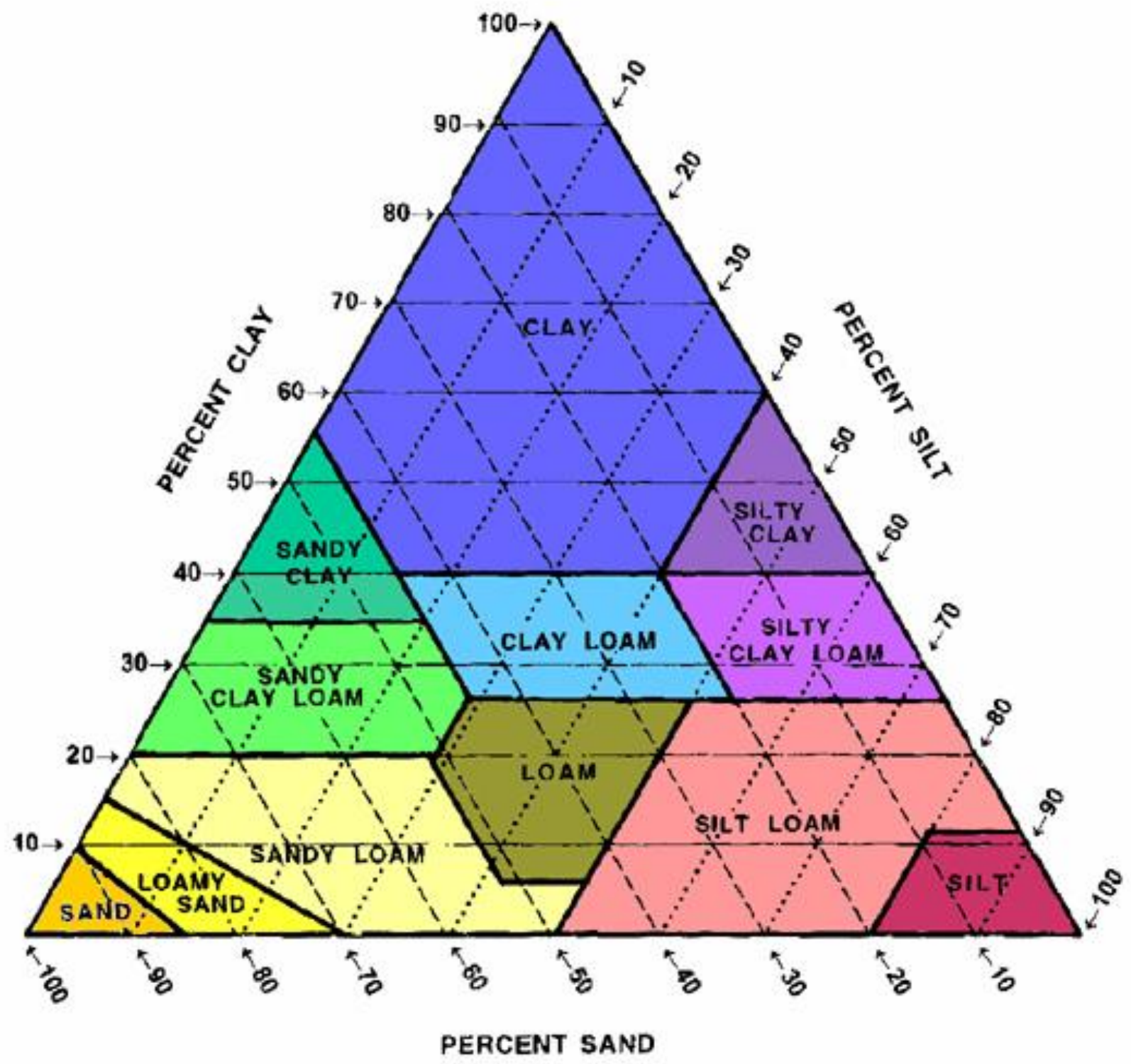




\section{Soil Structure}

Granular Prismatic Massive

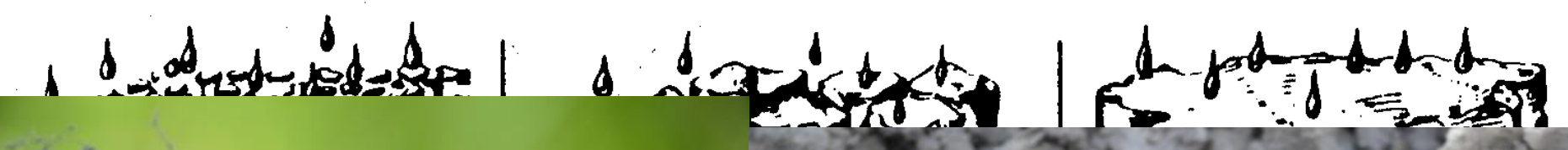
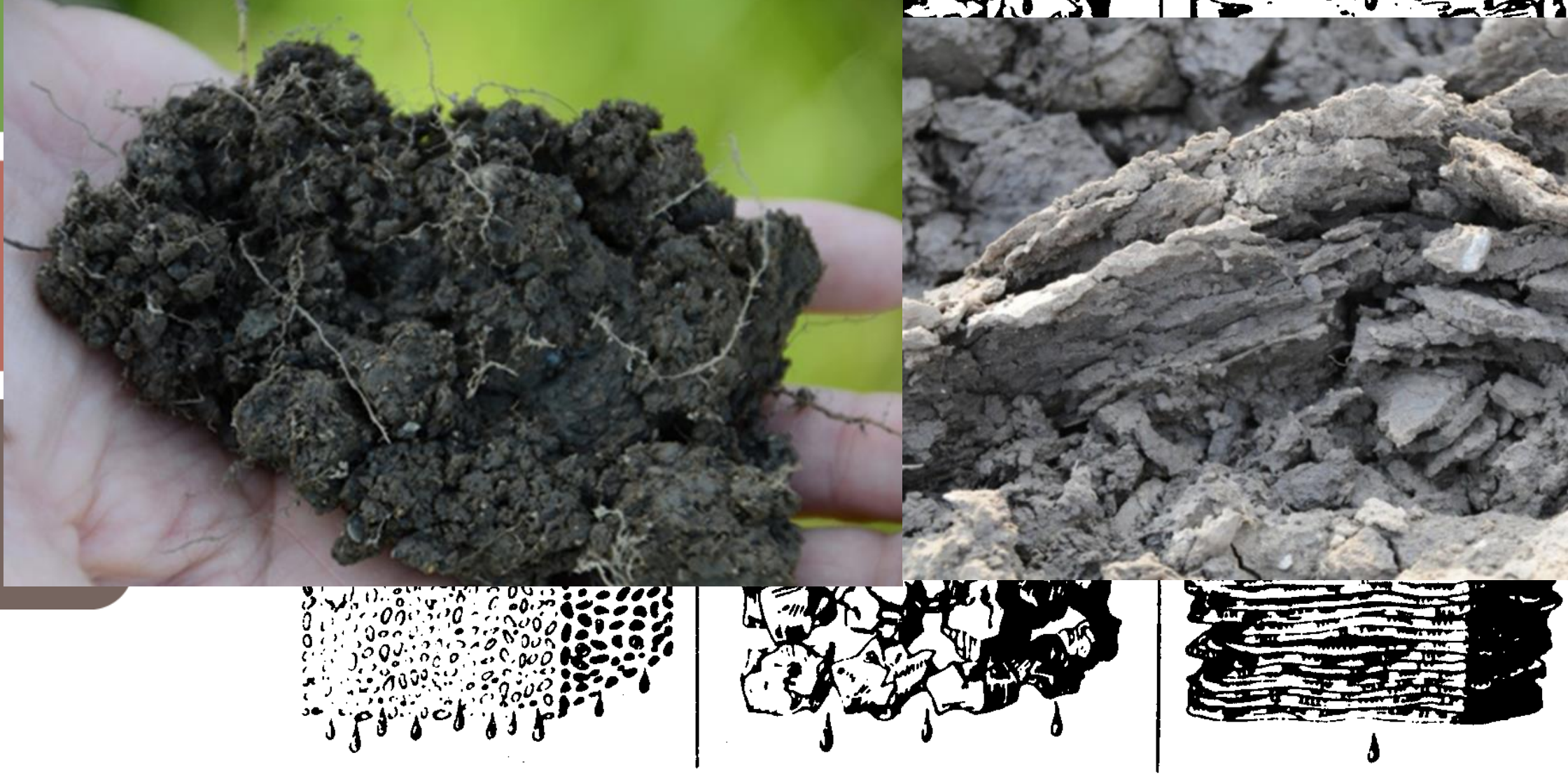


\section{Aggregate Stability}

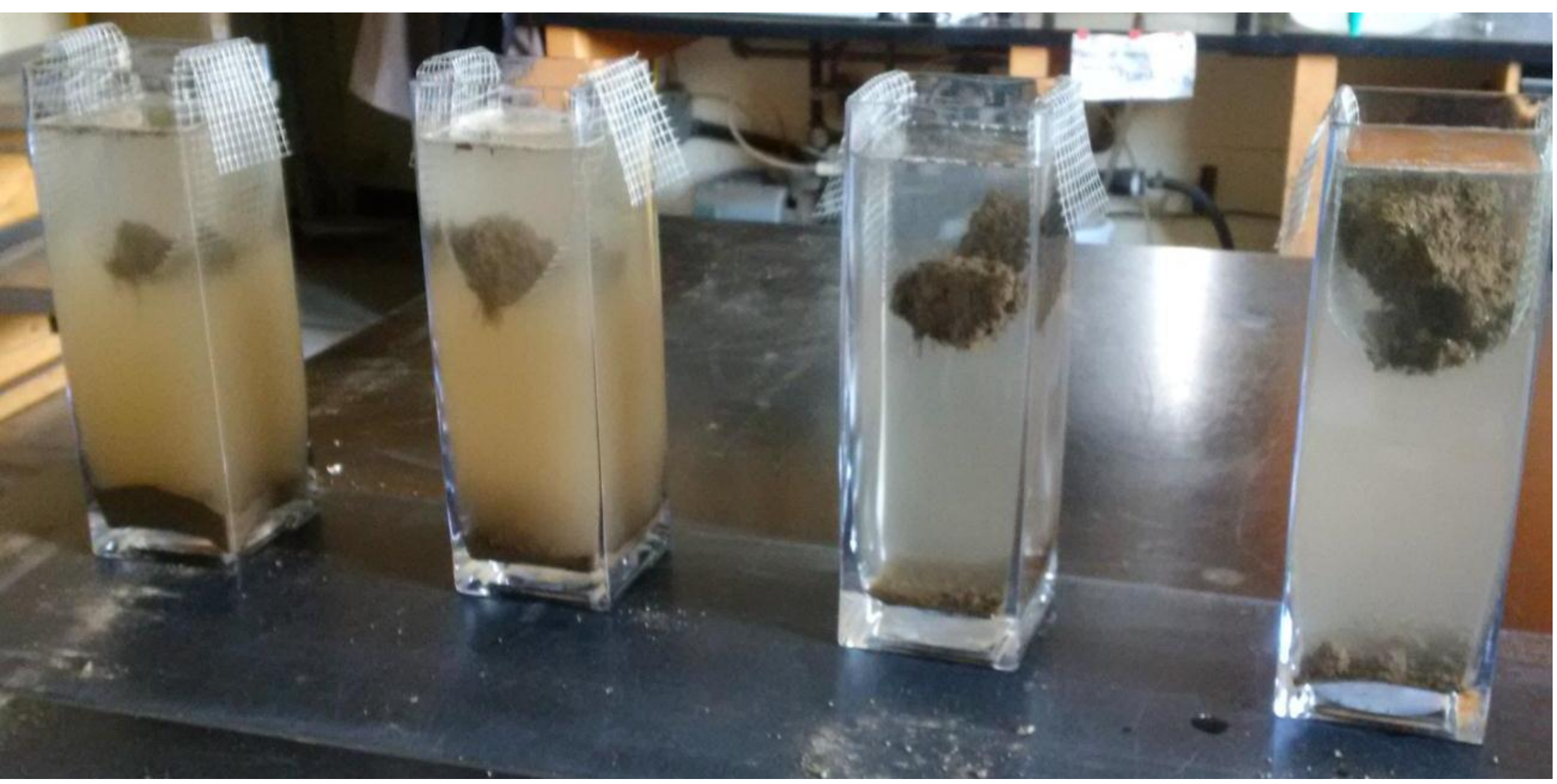




\section{Bulk Density}

- The mass of a certain volume of soil

- Includes solids and pores

- Sands 1.4 - $1.6 \mathrm{~g} / \mathrm{cm} 3$

- Other soils $1.2-1.4 \mathrm{~g} / \mathrm{cm} 3$

- Compacted soil up to $1.7 \mathrm{~g} / \mathrm{cm} 3$ 


\section{Available Water Capacity}

- The quantity of water a soil can store for plant use

- Calculated as the difference between water stored at field capacity and the wilting point 


\section{Available Water Capacity}

\begin{tabular}{|l|c|c|c|c|}
\hline Texture & O.M. & Clay & Silt & $\begin{array}{c}\text { Available } \\
\text { Water }\end{array}$ \\
\hline Sands & 1.2 & 3.3 & 2.6 & 2.9 \\
\hline Sandy loam & 1.8 & 10.3 & 35.8 & 9.7 \\
\hline Loam & 2.4 & 9.0 & 44.8 & 11.1 \\
\hline Silt loam & 2.3 & 5.9 & 52.1 & 10.7 \\
\hline & 4.5 & 17.4 & 56.2 & 18.8 \\
\hline Clay loam & 5.1 & 31.1 & 37.2 & 8.0 \\
\hline
\end{tabular}




\section{Soil Profile}

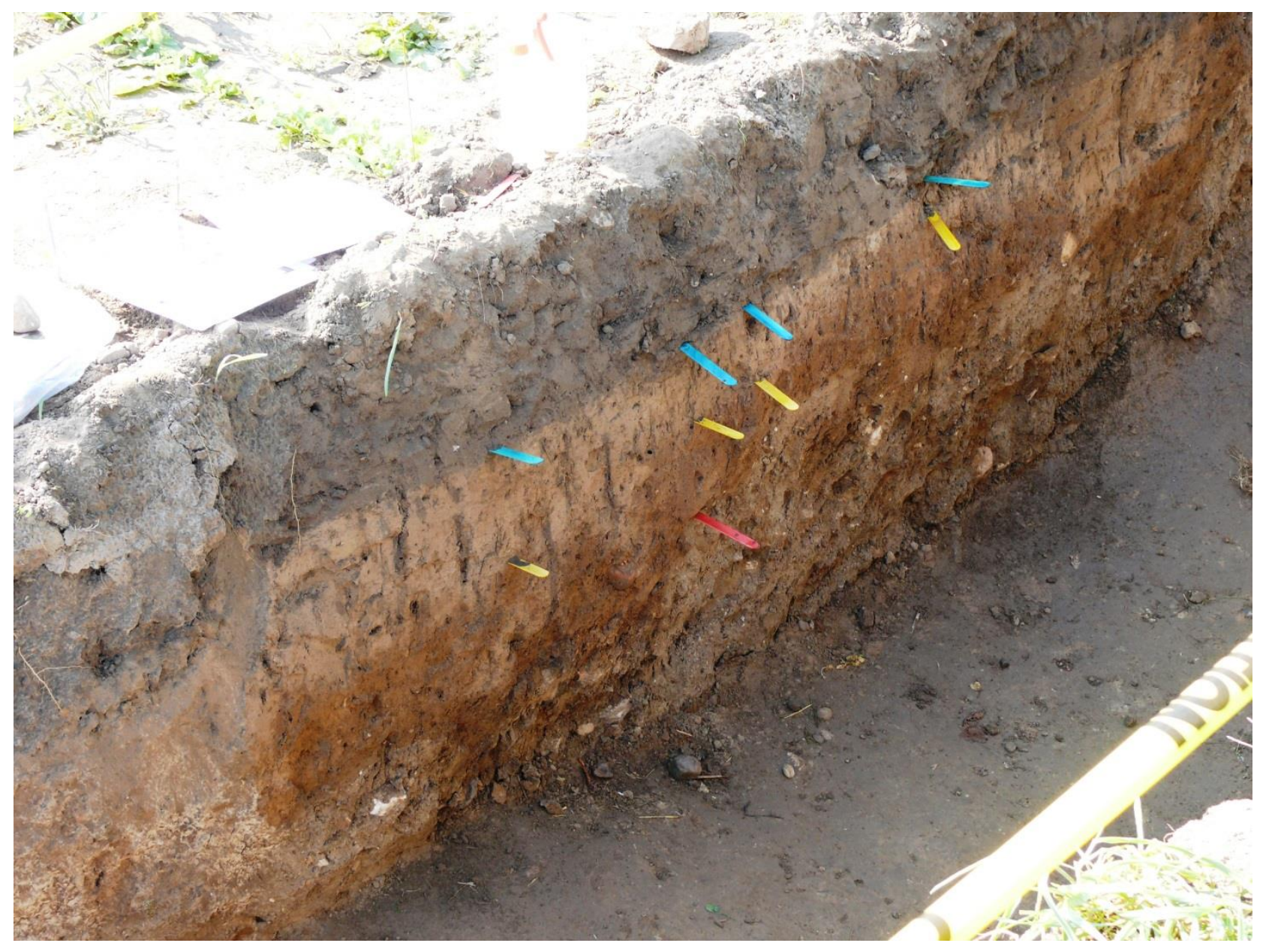




\section{Thanks!}

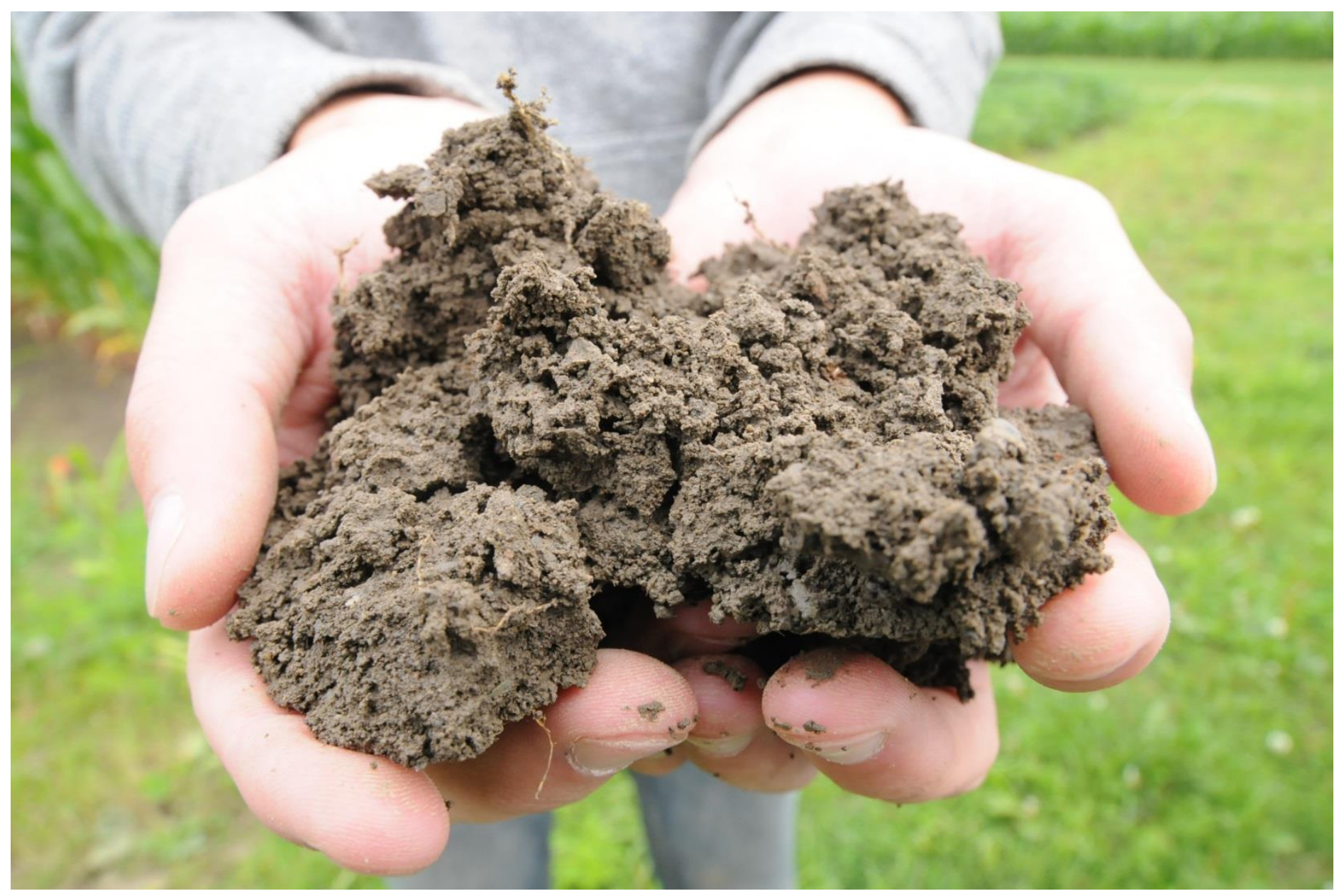

